The Psychological Benefits of Marriage and

Children in Rural Malawi

\author{
Shelley Clark \\ (McGill University) \\ Rachel Margolis \\ (Western University) \\ Cassandra Cotton \\ (Arizona State University) \\ Hans-Peter Kohler \\ (University of Pennsylvania)
}

Corresponding author: Shelley Clark, McGill University, Peterson Hall, 3460 McTavish

Montreal, Quebec, H3A 0E6; phone: 514-398-8822; e-mail: shelley.clark@mcgill.ca 


\title{
The Psychological Benefits of Marriage and Children in Rural Malawi
}

\author{
Abstract \\ Despite an extensive literature on the psychological rewards to marriage and children in high- \\ income countries, research on these relationships in low-income countries remains limited. This \\ paper draws on data from 2,926 adults interviewed in the Malawi Longitudinal Study of Families \\ and Health to examine how marital status, categorized as never, formerly, monogamously, and \\ polygynous married, and number of children is associated with psychological well-being. With \\ respect to marital status, we find that women in polygynous unions fare worse than \\ monogamously married women and this detrimental effect is stronger for women than for men. \\ Formerly married men and women of reproductive age experience the worst psychological \\ outcomes, although this association wanes with age. In contrast, the benefits of having children \\ is only evident among older Malawians, especially women. These findings offer novel insights \\ into the patterns of nearly universal marriage and high fertility that characterizes Malawi and \\ much of sub-Saharan Africa.
}


There is a large and robust literature which debates the psychological benefits (and costs) of marriage and children in high-income countries (for recent reviews see Kohler and Mencarini 2016; Nelson, Kushlev and Lyubomirsky 2014; Umberson, Thomeer and Williams 2013). This work is at least partly motivated by a desire to gain insights into the retreat from marriage and persistent low fertility that many countries in North America and Europe have experienced over the last few decades. In contrast, only a few studies have investigated the potential psychological implications of marriage and children in low-income countries (Cetre, Clark and Senik 2016; Conzo, Fuochi and Mencarini 2017; Deaton and Stone 2014; Margolis and Myrskylä 2011; Myroniuk 2017; Peiró 2006).

Studies situated in sub-Saharan Africa may be especially valuable as they could yield novel insights into the patterns of nearly universal marriage and sustained high fertility. They can also explore whether, and if so how, the psychological benefits of marriage and children differ in starkly different social, cultural, political, and economic contexts. Whether marriage and children are associated with better or worse psychological outcomes in sub-Saharan Africa is not immediately obvious. On the one hand, in settings where being married and having multiple children are fundamental to gaining social standing, one may anticipate that men and women reap larger psychological rewards to both marriage and children. In turn, these large psychological returns may at least partially explain the persistently high rates of marriage and rather slow declines in fertility found in much of sub-Saharan Africa (Bongaarts and Casterline 2013; Shapiro and Gebreselassie 2014). On the other hand, compared to high-income countries, decisions to marry and have children in sub-Saharan Africa may be more predicated on kinship obligations, economic considerations, and gender norms, than anticipated psychological benefits. Moreover, the high-costs of raising children in poor families with limited institutional support 
may increase parental stress and diminish children's psychological rewards (Aassve, Mencarini and Sironi 2015; Pollman-Schult 2014). Longitudinal research in Africa which focuses on the relationship between adults' psychological well-being and either children (Conzo, Fuochi and Mencarini 2017) or marital status (Myroniuk 2017) is currently rather limited.

This paper builds on this small, but growing, body of research in low-income countries by focusing on Malawi, a comparatively poor African country with nearly universal marriage and high-fertility. Our study uses three waves of the Malawi Longitudinal Study of Families and Health (MLSFH) to examine the relationship between adult psychological well-being and marital status (assessed as monogamously, polygynously, never, and formerly married) and fertility (measured as the number of children). We begin my assessing simple associations using randomeffects models. However, because there are likely strong selection effects into having more children and both into and out of marriage and because demographic events that occurred recently may have a different impact on psychological well-being than those that occurred long ago (Hagedoorn et al. 2006; Myrskylä and Margolis 2014; Strohschein et al. 2005; Williams and Umberson 2004), we also examine these relationships using fixed-effects analyses. Furthermore, given previous research, which indicates that these relationships vary by (a) how psychological wellbeing is measured (Deaton and Stone 2014) and (b) the age and sex of the respondent (Aassve, Goisis and Sironi 2012; Kohler, Behrman and Skytthe 2005), our analyses employ multiple measures of psychological well-being and are disaggregated by age and sex.

\section{BACKGROUND}

\section{Psychological Benefits of Marriage}

Because marriage often brings social status and represents an important life goal for many, it is likely to be positively associated with measures of overall life satisfaction (Waite and Lehrer 
2003; Waite and Gallagher 2000). Theories of social integration and emotional support suggest that marriage should also reduce individuals' feelings of isolation and help shield them from stress, anxiety, and depression (Wilson and Oswald 2005). However, the psychological advantages of marriage may vary by sex and age. In high-income countries, men, for example, tend to derive more psychological benefits from marriage than women (Kim and McKenry 2002; Kohler, Behrman and Skytthe 2005; Stutzer and Frey 2006; Waite and Gallagher 2000; Williams and Umberson 2004). Age may also modify the psychological gains of marriage. Although little is known about the psychological rewards of marriage over the life course (Umberson, Thomeer and Williams 2013), the protective effects were evident at older ages (Hagedoorn et al. 2006). In addition, the psychological benefits differ according to the types of union status (e.g. never vs. formerly married; first marriage vs. remarriage, cohabitation vs. marriage) (Umberson, Pudrovska and Reczek 2010; Waite and Gallagher 2000). Among unmarried men and women, those who were divorced or widowed had worse mental health outcomes than those who were never married (Kim and McKenry 2002; Williams 2003). Longitudinal studies suggest that accounting for time-constant selection effects reduced, but did not eliminate, the beneficial effects of being married compared to being never married (DeMaris 2018; Musick and Bumpass 2012; Zimmermann and Easterlin 2006). In contrast, the immediate negative effects of being formerly married were often stronger, suggesting a significant short-term mental toll of divorce and widowhood (Ballas and Dorling 2007; Strohschein et al. 2005).

Research linking union status to psychological well-being in low-income countries is scarce. Cross-sectional analyses found a generally positive association between marriage and life satisfaction across 15 countries with the notable exception of the only African county included, Nigeria (Peiró 2006). Three studies in Africa, which used a dichotomous measure of marital 
status and focused on older adults (age 45 and above), reported better mental health or quality of life among those married compared to those unmarried (most of whom were formerly married) (Kohler et al. 2017; Myroniuk 2017; Ralston 2017). Unfortunately, these prior studies did not present marital results disaggregated by gender or age group. Moreover, to our knowledge, no previous study has assessed differences between monogamous and polygynous unions, which are important types of marriage in this region.

\section{Psychological Benefits of Children}

The relationship between children and psychological well-being is theoretically more complex. Like marriage, many people view having children as an important life goal. One would, therefore, expect that having children would be positively associated with overall life satisfaction, but the evidence from high-income countries is surprisingly mixed (Kohler, Behrman and Skytthe 2005; Myrskylä and Margolis 2014; Pollman-Schult 2014). Several studies

found associations between having children and recent experiences of negative emotions because children may increase parents' level of stress, anxiety, depression, and frustration (Deaton and Stone 2014; Evenson and Simon 2005; Nelson, Kushlev and Lyubomirsky 2014). It is important to note, however, that while much of the research in high-income, high-fertility countries focuses on the psychological impact of becoming a parent (i.e. having a first child), the work in lowincome, low-fertility countries assess the relationship between psychological well-being and fertility (i.e. number of children), as virtually all adults become parents.

Having young children also appears to be more disadvantageous to women's psychological wellbeing than men's, presumably because of persistent gender inequalities which oblige women to perform the majority of the more mundane, tedious, and stressful tasks of child care (Kohler, Behrman and Skytthe 2005; Scher and Sharabany 2005). These findings are 
consistent with longitudinal studies showing that life satisfaction changes in anticipation of and shortly after childbirth (Clark and Georgellis 2013; Clark et al. 2008; Frijters, Johnston and Shields 2011; Rizzi and Mikucka 2015). Evidence also suggests that even if parents of reproductive age receive few, if any, psychological benefits from children, older parents enjoy the social interaction and emotional support provided by adult children (Deaton and Stone 2014; Margolis and Myrskylä 2011; Umberson and Williams 1999). Research from rural South Africa suggests that older women, in particular, are likely to receive emotional support from relatives (many of whom are presumably their adult children) (Jennings, Mkhwanazi and Berkman 2018). Because institutional support for child care tends to reduce the costs of raising young children and social security programs for the elderly reduces dependence on adult children (Aassve, Mencarini and Sironi 2015; Pollmann-Schult 2018), some researchers have hypothesized that the changing effect of children with age will be more pronounced in contexts with weak social policies (Margolis and Myrskylä 2011).

Limited social policies to support early childcare may help explain the strong negative associations between the number of children and measures of life satisfaction found most lowincome countries, despite the high social value placed on children (Cetre, Clark and Senik 2016; Deaton and Stone 2014; Margolis and Myrskylä 2011). These findings stand in contrast to numerous studies in Africa which showed that women who are unable to have children are more likely to suffer from depression (Barden-O'Fallon 2005; Hess, Ratchneewan and Gililland, 2018). These findings illustrate that although becoming a parent is expected and essential to one's psychological well-being, higher fertility brings few psychological rewards. In the only longitudinal analyses conducted in Africa, Conzo and colleagues (2017) showed that rural Ethiopian women who gave birth in the last five years reported significantly lower levels of life 
satisfaction, but that total number of children was not significantly associated with life satisfaction for either men or women of reproductive age. In contrast, having more children was associated with greater life satisfaction for men, but not women, who are aged 50 or older.

\section{Study Site}

Our analysis is situated in rural Malawi where both marriage and parenthood are nearly universal. Malawi is one of the poorest countries in the world, ranking 170 out of 188 countries according to the Human Development Index (UNDP 2016). Although its population is small (less than 20 million), it hosts considerable religious, ethnic, and cultural diversity. The northern region of Malawi is patrilineal and largely Christian, whereas residents in southern Malawi are primarily Muslim and follow matrilineal kinship practices. Consequently, although fertility is high across all regions, Malawians follow an array of marital practices.

As in other parts of sub-Saharan Africa, marriages traditionally represented the uniting of two kinship lineages, and kin are heavily involved in spousal selection (Fortes 1958). Over the past four decades, there has been a notable rise in companionate marriages with individuals choosing their spouses and kin granting approval. As a result, conjugal bonds have strengthened relative to consanguineous ties. Yet, despite this profound shift in the union formation process, over $99 \%$ of both men and women have married by age 40 . Women continue to marry at a comparatively young age (17.8 years for women and 22.6 for men) (NSO and ICF Macro 2011), however many marriages do not last. Within 20 years of marriage, $44 \%$ of unions will dissolve. Most of these unions (77\%) will end via divorce rather than widowhood (23\%) (Clark and Brauner-Otto 2015). Remarriage rates are also very high. Hence, despite considerable union instability, a relatively small percentage are currently formerly married (13\% of women and only 
$4 \%$ of men) (NSO and ICF Macro 2011). Polygyny is common, with more than $15 \%$ of rural women reporting being in a polygynous union (NSO and ICF Macro 2011).

With respect to children, Malawi, like other countries in sub-Saharan Africa, is strongly pro-natalist (Dyer 2007). During the period of our study (2006-2010), fertility rates in rural areas declined slightly from 6.4 to 6.1 (NSO and ICF 2005, 2011). Moreover, African women are primarily responsible for childcare with little assistance from fathers or relatives (Clark et al. 2017). Motherhood before first marriage is relatively rare (about 10\%) (Clark, Koski and SmithGreenaway 2017), but because of high union instability, more than half of Malawian women will become single mothers before age 45 (Clark and Hamplová 2013).

\section{Hypotheses}

The particular fertility and marital context of rural Malawi guides our main hypotheses as we examine the relationships between marriage and children and psychological wellbeing.

Malawians of reproductive age: Our first set of hypotheses pertain to adults of reproductive age (ages 15 to 49). Because marriage confers social standing and potentially emotional support, we expect that both men and women in marriage would be psychologically better off than those who are unmarried. However, there are likely substantial differences by gender and across marital status categories. Specifically, we anticipate that the difference between those in monogamous unions and those who are never-married will be positive, but small, primarily because nearly all men and women enter into marriage. In contrast, we expect that being divorced or widowed will be associated with adverse psychological effects, which will be stronger for women than men because formerly married women of reproductive age will face greater stigma and economic pressures in order to care for themselves and their children. As in high-income countries, the negative shock of divorce or widowhood will be strongest shortly after the event. 
With respect to polygyny, we expect that women in polygynous unions will have worse outcomes than those in monogamous unions. These expectations are consistent with prior research that shows a negative association between polygyny and women and children's physical health (Bove and Valeggia 2009; Lawson and Gibson 2018; Madhavan 2002; Smith-Greenaway and Trinitapoli 2014). The relationship between men's psychological wellbeing and polygyny is more ambiguous. On the one hand, men with multiple wives may enjoy greater social prestige. On the other hand, the emotional and economic stress of maintaining more than one household may be a psychological drain as polygynous unions are prone to more intra-family conflicts (Bove and Valeggia 2009). As with those who are formerly married, we speculate that recently entering into polygynous unions may exacerbate these negative effects, as both men and women adjust to these new marital arrangements.

Fertility may also be associated with psychological well-being. Given the centrality of children in the lives of women, Malawian women of reproductive age are likely to experience both greater psychological costs and benefits of children than men. Persistent gender norms dictate that women bear more of the burden of childrearing, but also receive greater social approbation for such care. These countervailing factors may dampen any overall gender differences, particularly given the high value that men also place on having children (Nauck and Klaus 2007). Finally, even if the pros and cons of motherhood balance out over time, the psychological demands on women may be most acute in the first few years after childbirth when the child is young

Older Malawians: As Malawian men and women age beyond their reproductive years, the psychological benefits of marriage and children may change. Marital status may become less important among older Malawians, who are less dependent on co-parents help raise young 
children. Furthermore, the stigma associated with being formerly married, particularly widowed, may diminish as it become increasingly more common. These hypotheses reflect previous studies showing a weak negative correlation with those formerly married and physical health and no association with having recently been widowed or divorced (Myroniuk 2017). In addition, building on the work of Margolis and Myrskylä (2011), we expect that the benefits of having adult children will be more evident among older Malawians, although in contrast with Conzo, Fuochi and Mencarini (2017), we anticipate that the psychological gains will be as large, if not larger, for older women than for older men, given the high level of dependence of older women on adult children in Malawi.

\section{DATA AND MeTHODS}

\section{Data}

We draw on one of the only large-scale longitudinal studies in sub-Saharan Africa with repeated measures of adult mental health, union status, number of children, and important sociodemographic variables, the Malawi Longitudinal Study of Families and Households (MLSFH) (http://malawi.pop.upenn.edu ). The MLSFH was conducted in three rural sites: Rumphi in the northern region, Mchinji in the central region, and Balaka in the southern region. Previous analyses indicate that the sample is broadly representative of rural Malawi as a whole (Kohler et al. 2015). Our analyses rely on data from three waves of the MLSFH, conducted in 2006, 2008, and 2010, which included both reproductive age and older adults and asked questions on mental health. ${ }^{1}$ Further details about the MLSFH cohort and the data collection process are available in

\footnotetext{
${ }^{1}$ The MLSF began in 1994 with a sample of about 1,500 married women and their partners. In 2004, a sample of about 1,500 youths (aged 15 to 24), many of whom where unmarried, were added to the study. Lastly, about 800 parents of participants were included in 2008 to capture an older population.
} 
Kohler et al. (2015). The MLSFH data used in these analyses are available at https://malawi.pop.upenn.edu/malawi-data-mlsfh.

\section{Analytic Sample}

We divide our sample into reproductive age (younger than age 50) and older Malawians (age 50 and older). A total of 2,661 respondents aged 15 to 49 were interviewed at least twice between 2006 and 2010. In addition, previous studies have shown issues of inconsistency in reports of total number of children and of child mortality across early waves of the MLSFH (Bignami-Van Assche, Reniers and Weinreb 2003). These discrepancies likely reflect the erroneous inclusion of foster children or omission of deceased children in the reported number of children ever born. We, therefore, exclude respondents $(n=186)$ that reported an improbably large number of children born between waves (greater than four children) and respondents $(n=370)$ who reported a decrease in the number of children ever born across waves. Sensitivity analyses which include these respondents show no impact on our findings regarding union status or number of children. After further excluding 36 individuals missing either the dependent or independent variables, our analytic sample of reproductive age adults includes 2,193 respondents interviewed at least twice between 2006 and 2010 (1,312 women and 881 men). These individuals contributed 5,039 observations over the three waves. In addition, we rely on a sample of 426 women and 307 men aged 50 years or older interviewed at least twice between 2006 and 2010. These older respondents contributed a total of 1,622 observations across all waves.

\section{Measures}

\section{Dependent Variables}


In this paper, we use the term "psychological wellbeing" to encompass an array of indicators ranging from subjective wellbeing to mental health. Some studies have focused on global assessments of overall life satisfaction, which provide a broad judgment about how content individuals are with their achievements and status in life (Clark et al. 2008; Kohler, Behrman and Skytthe 2005; Kohler and Mencarini 2016; Margolis and Myrskylä 2011; Myrskylä and Margolis 2014). Other studies focused on the recent experience of negative emotions or hedonic states (e.g. anger, frustration, anxiety, depression), which may be indicative of poor mental health (Brown 2000; Deaton and Stone 2014; Evenson and Simon 2005; Nomaguchi and Milkie 2003; Umberson, Thomeer and Williams 2013).

Because children and marital status may affect different indicators of psychological wellbeing differently, we assess three related measures of psychological wellbeing. For our first measure of psychological wellbeing, we use the Short Form-12 (SF12), a widely used measure of overall social/emotional functioning, subjective wellbeing, and overall health-related quality of life, to measure overall mental health. The SF-12 ranges from 0 to 100 with higher scores associated with better mental health. This measure has been implemented and validated in many different contexts (Corcoran and Fischer 2007; Ware, Kosinski and Keller 2001).

The second measure is a depression and anxiety index (DAX) (Kohler et al. 2017). The DAX is derived from two questions in the SF-12 instrument. Respondents were asked 1) "How much of the time during the past 4 weeks have you felt calm and peaceful?" and 2) "How much of the time during the past 4 weeks have you felt downhearted and depressed?" Answers for both questions ranged from "none of the time", "a little, some", "most", or "all of the time". Responses are coded as 2 (no depression/anxiety) when respondents rarely felt depressed and felt calm and peaceful most or all of the time. Respondents are coded as 1 (mild depression/anxiety) 
when they experienced both depression and calm some of the time. Those who rarely felt calm and felt depressed most of the time are coded as 0 (moderate depression/anxiety). Thus, on this 3-point scale higher values correspond to lower levels of depression and anxiety. Alternative specifications such as a dichotomous measure of five-point Likert scale of depression yield similar results. Because both the DAX and mental health score are derived from questions in the SF-12, they are not surprisingly correlated. Analyses of DAX, however, allow us to focus more directly on this specific dimension of psychological wellbeing, which is often associated with both union status and fertility.

The final measure of psychological wellbeing is life satisfaction. Respondents were asked "I am interested in your general level of wellbeing or satisfaction with life. How satisfied are you with your life, all things considered?" Responses range from 1 (very unsatisfied) to 5 (very satisfied). All three dependent variables are then standardized to facilitate comparable interpretations of results across outcomes.

\section{Independent Variables}

Our key independent variables capture union status and measures of fertility at each wave. We use four categories of union status: never, formerly, monogamously, and polygynously married. For our analyses of respondents aged 50 and older, we exclude the category of never married as no respondents reported this status. The absence of never-married older adults likely reflects the selection of the original sample in 1998, which was limited to ever-married adults. This bias is

not likely to be large as only $0.1 \%$ of women and $0.6 \%$ of men are never-married by age 40 (NSO and ICF Macro 2011). Limited sample sizes prohibit us from further disaggregating formerly married individuals between those widowed or divorced. The majority of men (91\%) and women (72\%) below the age of 50 are divorced, whereas widowhood is more common 
among older respondents ( $73 \%$ of women and 58\% men 58\%). Monogamously married individuals serve as our reference group as it is the most common marital state. Fertility is measured by the total number of children, which ranges from 0 to 14 for women and 0 to 25 for men with the upper bounds driven by polygynous unions. Given the high level of reporting errors noted above, we argue that our measure of "number of children" may be best interpreted as number of living children rather than children ever born. Sensitivity analyses show that there are no notable differences using alternative specifications, such as categorical measures of number of children and a binary indicator for having at least one child.

All models also control for potential explanatory variables related to wellbeing including respondent's age, education, wealth, and religion. Education is measured as none, primary, or secondary or higher education. The wealth measure uses a count of household ownership of 14 different assets. Those owning fewer assets may be considered poorer compared to those owning many assets, although we note that in our study sites nearly all respondents are poor by global standards. Religion is categorized into six broad groups, including Catholic, Muslim, Protestant, African Independent Churches, Pentecostal, and other or no religion. To account for the likely correlation between physical and mental health, models control for respondent's physical health, using the SF-12 Physical Health Component Score, which ranges from 0 to 100. Lastly, we include a control for the region of the study site.

\section{Analytic Approach}

We estimate separate models for each outcome: overall mental health, depression and anxiety, and life satisfaction. Random effects models by sex and age group (reproductive ages and older adults) are employed to examine the cross-sectional association between current marital status and number of children. All random effects models control for respondent's age, education, asset 
ownership, religion, physical health score, region, and study wave. In addition, fixed effects models are used to examine changes in psychological wellbeing in response to recent changes in marital status and number of children among women and men in reproductive ages. These analyses assess the relationships for respondents who recently (within the last two years) entered into a marriage, left a marriage, transitioned into or out of a polygynous union, or had a child. In these models, we also control for changes in respondents' wealth, physical health, and for general time trends. These fixed effects models implicitly control for all observed and unobserved time-invariant characteristics of respondents that may influence selection into and out of marriage and having additional children. We do not estimate fixed effects models for men and women aged 50 and above because too few older adults report changes in numbers of children.

For ease of interpretation, the standardized coefficients and $95 \%$ confidence intervals pertaining to union status and children are presented in Figures 1 to 3 with the full results in Appendices 1-3. The figures report the magnitude of the effects for having children as having

five versus none, because the magnitude of the effect of one additional child is small even when it is statistically significant. Five children represents a difference of approximately two standard deviations.

\section{RESULTS}

\section{Descriptive Characteristics}

Table 1 provides descriptive characteristics for men and women in our sample in 2006. Most respondents reported little or no depression or anxiety, corresponding to a relatively high DAX value. The average respondent also reported being at least somewhat satisfied with his or her life. Women had significantly worse mental health scores and experienced DAX more often than men 
in both age groups (for all comparisons $p<.001$ ). Men also reported higher levels of overall life satisfaction than women at younger $(p<.001)$ and older $(p<.01)$ ages. Older respondents had lower mental health scores, experienced more depression and anxiety, and had lower levels of life satisfaction than their younger counterparts. This decline with age was significant for women across all three measures of psychological wellbeing $(p<0.05)$ and for men with respect to their overall life satisfaction $(p<0.001)$.

(insert Table 1 about here)

With respect to marital status, more than half of men and women in both age groups were in monogamous unions. A substantially larger fraction of younger men than younger women were never married in 2006 reflecting their later age of marriage. In comparison, many more women reported being in a polygynous union than men as a result of both the nature of such unions (one man is married to multiple wives) and typically large spousal age differences in polygynous unions. Polygyny is also more widely practiced in the largely Christian and patrilineal northern region of Malawi. Older women and men were more likely to be formerly married or in polygynous unions than younger respondents. However, it is important to keep in mind that comparatively few men $(<3 \%)$ are currently formerly married, even in the older age group. This reflects gender disparities in age of divorce and widowhood as well as rates of remarriage.

Related to these gender differences in marriage, younger men had on average one less child than younger women (2.4 vs. 3.6). Older men and women both reported about eight children, reflecting the very high fertility in this context. On average, there was a 25 -year age gap between our younger and older cohorts. 
The stark educational disparities also reflect societal gender inequalities, which are more pronounced in rural areas. Women aged 15 to 49 were twice as likely as men in this age group to have no education, although there was evidence of marked improvements for both men and women in education over time. In general, our respondents had limited wealth, owning fewer than five of the 14 assets measured. They reported average physical health with a slight expected decline with age. Lastly, they followed a wide range of religions with roughly equitable distribution among Catholics, Muslims, Protestants, African Traditionalist, and Pentecostal sects.

\section{Multivariate Results}

The first set of results focuses on women and men of reproductive age. Key standardized coefficients are plotted in Figure 1 (full results in Appendix 1). We found significant differences in psychological wellbeing for women by union status. Across all three measures of psychological wellbeing, women in polygynous unions reported significantly worse outcomes than women in monogamous marriages, potentially reflecting both greater mental and emotional strains in multi-partner unions as well as selection of less educated and poorer women into polygynous unions. The poorest mental health, however, is found among formerly married women. Formerly married women not only reported worse mental health than monogamously married women, but they were also disadvantaged compared to never married and even polygynously married women. The differences between monogamously and formerly married women were large, between one third and half of a standard deviation. In contrast, women in monogamous unions and those who had never been married report similar psychological wellbeing.

(insert Figure 1 about here) 
Our results for men are also shown in Figure 1 (full results in Appendix 1). Similar to the findings for women, formerly married young men experienced the worst mental health. Formerly married men had almost half of a standard deviation lower SF-12 than monogamously married men. For DAX, formerly married men were more than one quarter of a standard deviation lower than monogamously married men. The strength of these findings is particularly striking given the low proportion of men who were currently formerly married in this age group. Unlike for women, men in polygamous unions do not have worse psychological outcomes than men in monogamous unions. In fact, polygamous men report slightly better (but not significant) outcomes (Figure 1).

\section{(Insert Table 2 about here)}

Tests of gender differences using an interaction term show no significant differences in the psychological wellbeing of formerly married men and women (Table 2). The relative psychological benefits of marriage for men, however, differed in other respects. Never married men experienced significantly worse overall mental health than monogamously married men. The most striking gender differences pertain to polygyny. Being in a polygynous union is associated with significantly more depression and anxiety for women than for men. Polygnynous women also had lower SF-12 scores and life satisfaction than polygynous men, although the differences are only marginally significant $(p=.07)$. Lastly, our analyses of the relationship between fertility and psychological wellbeing (Figure 1) shows that none of our three measures of psychological wellbeing was significantly associated with fertility for men or women. Nor were there any significant gender differences with respect to fertility among men and women of reproductive age (Table 2$)$. 
Our second set of analyses estimates fixed effects models to examine changes in psychological wellbeing in response to recent changes in marital status and fertility among women and men of childbearing ages (Figure 2). These analyses examine changes within the last two years; specifically, whether the respondent remained never-married, transitioned into or out of a union, or had a child. We find negative effects of recently becoming formerly married for all three measures of wellbeing for women. In contrast, we find no associations with changes in psychological wellbeing arising from movement into a polygynous union, although the coefficients for both SF-12 and DAX are negative. With respect to fertility, we find no effects on mental health or DAX, and decreases in life satisfaction. Women who had a child in the last two years reported being significantly less satisfied with their lives overall.

(insert Figure 2 about here)

The fixed effects results for men are largely similar to those for women. The strong negative association between having recently become formerly married and SF-12 and DAX remained very strong. These findings suggest that like women, the end of marriage through divorce or spousal death takes a toll on men's mental health, yet, it does not significantly impact their life satisfaction. In contrast to women, however, the birth of a child within the last two years had no significant impact on any of men's three measures of psychological wellbeing. In our final set of analyses, we examine associations between marriage and fertility with psychological wellbeing for those aged 50 and older. In contrast to our findings for reproductive aged individuals (Figure 1), where marital status rather than fertility shaped individuals' psychological wellbeing, Figure 3 shows that older Malawians derive psychological benefits from having children, but not from being married. There was no association between marital status and SF-12, DAX or life satisfaction at older ages for men or women. This finding is 
especially interesting given that the proportion of formerly married women doubles in this older cohort. Nonetheless, although the negative psychological implications of being formerly married declined with age for both men and women, this difference by age is only significant for women. Table 3, which tests for interactions by age group, finds that younger formerly married women experienced significantly worse psychological outcomes than younger formerly married women across all three measures of psychological wellbeing.

(insert Figure 3 \& Table 3 about here)

Older women also experienced significant gains from each additional child across all three measures of psychological wellbeing. The magnitude of this effect is rather small, for example, increasing their SF-12 score by only 0.04 of a standard deviation for each additional child (Appendix 2). As shown in Figure 3, this implies that women who have five more children (a difference of about two standard deviations) reported an increase in their mental health of 0.22 of a standard deviation. Interaction analyses shown in Table 3 finds that older women with higher fertility fared significantly better across all three measures of psychological wellbeing than young women, whereas older men with more adult children experienced a psychological advantage only with respect to life satisfaction.

\section{DISCUSSION}

Our paper offers some of the first insights into to complex relationship between two key demographic factors, union status and number of children, and men's and women's psychological well-being in sub-Saharan Africa. In particular, it offers a nuanced picture of these relationships by going beyond a simple dichotomous measure of marital status, examining multiple indicators of psychological well-being, and assess differences by gender and age. Most, 
but not all, of our findings support our initial hypotheses and are consistent with the limited research in low-income countries.

With respect to reproductive-aged adults, we find that marital status is much more strongly associated with psychological well-being than number of children. Our expectation that never-married adults will have only slightly worse psychological well-being than those monogamously married is largely met. In fact, we find that only the measure of men's overall mental health is significantly negatively associated with being never-married, possibly reflecting the fact that virally all Malawians will eventually marry.

In contrast, and as anticipated, our results indicate that formerly married men and women of reproductive age suffer from significantly worse mental health and greater depression and anxiety. Given that about 50\% of women in Malawi will experience a union dissolution and spend at least some portion of their lives as a formerly married single mother (Clark and Hamplovà 2013), this tax on women's (and men's) psychological wellbeing is appreciable. Nonetheless, contrary to our expectation and pervasive gender norms which typically hold women, more than men, accountable for the care and economic support of children following divorce, we find no evidence that being formerly married is more detrimental to women and men. Findings from our fixed effects analyses are consistent with previous research from high income countries. They suggest that the detrimental effects associated with being formerly married are not primarily influenced by selection of individuals out of unions, but rather the process of union dissolution has an acute effect.

In addition, our study offers the first evidence of important gender differences with respect to the relative benefits of monogamous and polygynous unions. Although the practice of polygyny has diminished over the past 50 years, it has not disappeared and remains relatively 
common in rural areas. In our sample, one in five women were in a polygynous union. Although polygyny may offer women some psychological advantages compared to being formerly married, its benefits are significantly lower than those for women in monogamous unions. Even after controlling for the lower education, greater poverty, and poorer physical health of polygynous women (Bove and Valeggia 2009), they exhibit greater psychological vulnerability. However, our fixed effects results show no statistically significant differences between women transitioning into and out of polygynous unions. These results suggest either that psychologically more vulnerable women select into polygynous unions or that the psychological consequences of being in a polygynous union are not apparent within the first two years of marriage. In comparison, there are no negative implications of polygyny for men. Indeed, the association is positive, but not significant. These findings suggest that any stress incurred from maintaining more than one household is counterbalanced by the prestige men derive from having multiple wives.

As we hypothesized, the impact of being formerly married is considerably less for Malawians beyond their reproductive years (especially for women). These findings stand in contrast to research from high-income countries that indicates that benefits of marriage extend to older ages (Hagedoorn et al. 2006). The decline in the importance of marriage may reflect the greater social acceptability of being unmarried at older ages, particularly for women. It may also be related to the economic strain facing young formerly married mothers with dependent children compared to the economic support older formerly married women may receive from their adult children. Finally, it may suggest that the hardship and stigma associated with divorce (the primary driver of union dissolution before age 50) is less than that associated with widowhood, which becomes more common at older ages. 
The relationships between fertility and psychological wellbeing are quite different than those for marital status. Despite the value and centrality of children in the lives of Malawians (Dyer 2007), the number of children is not correlated with any measure of men's or women's psychological wellbeing during their reproductive years. This is consistent with our expectations and findings from rural Ethiopia (Conzo, Fuochi and Mencarini 2017), but differs from crosssectional analyses of low-income countries showing a strong negative association between both negative emotions (Deaton and Stone 2014) and life satisfaction (Margolis and Myrskylä 2011). In addition, we find that women who had a child in the two years report significantly lower overall life satisfaction, although having recently had a child is not associated with diminished overall mental health or depression for women and has no association with men's psychological measures. These findings suggest that any overall negative effects may be temporary and associated primarily with the care of infants and toddlers. Furthermore, at least in very poor rural areas of sub-Saharan Africa, the psychological costs of raising children in poor households are largely offset by psychological rewards in settings that highly value children (Nauck and Klaus 2007).

Among older Malawians, having more (adult) children is associated with better outcomes across all three psychological measures for older women and greater life satisfaction for older men. These findings differ from the study in rural Ethiopia which found that only older men who had more children experienced heightened life satisfaction (Conzo, Fuochi and Mencarini 2017). These results highlight the importance of having adult children for both men and women particularly in contexts with a limited social safety net (Margolis and Myrskylä 2011). The relatively greater benefits for older women than men likely reflects women's greater dependence 
on adult children for both economic and emotional support at older ages (Jennings, Mkhwanazi and Berkman 2018).

\section{Limitations}

To our knowledge, the MLSFH is one of only two extant longitudinal surveys that capture both measures of psychological wellbeing and demographic events in sub-Saharan Africa. Such data collection, however, presents multiple theoretical and logistical challenges. One challenge is whether measures of mental health and depression used in high-income countries are valid in rural sub-Saharan Africa. Although the instrument used in this study has been used and validated in several different settings (Corcoran and Fischer 2007; Ware, Kosinski and Keller 2001), concepts about emotional states and mental health may vary considerably across contexts. Similar concerns have been raised with respect to measures of overall life satisfaction. To some extent, these issues are mitigated in fixed effects models, assuming that respondents interpret the questions in the same manner across waves. Cross-national comparisons of our findings, however, should bear this concern in mind.

Another issue is properly capturing number of children in a context where child fostering is widely practiced. Although fostering tends to be more common with children above the age of six, as we noted above, Malawians may include co-residential children as their own when asked questions about their total number of children ever born (Bignami-Van Assche, Reniers and Weinreb 2003). Hence, our results likely reflect social, rather than strictly biological, parenting.

Despite these limitations, by providing a more detailed picture of the relationships between fertility, marriage, and psychological wellbeing in a low-income setting, our paper makes several contributions. First, we provide further insights into the particularly higher rates of marriage and remarriage in rural Malawi, and elsewhere in sub-Saharan Africa, by highlighting 
the psychological strain experienced formerly married individuals, particularly for women of reproductive age. These findings reinforce other studies on the challenges of single motherhood in sub-Saharan Africa and the need to develop more programs and social policies to assist these women and their children (Clark and Hamplovà 2013; Clark et al. 2017). Second, given that women in polygynous unions suffer from greater depression and anxiety than women in monogamous unions, further studies are required to investigate whether these psychological factors contribute to higher levels of union instability or overall declines in polygyny in subSaharan Africa. Third, our findings coupled with those from Conzo and colleagues (2017) suggest that in rural Africa children come at minimal psychological cost for younger adults and offer significant psychological benefits at older ages. Such findings can help explain why fertility rates remain persistently high in these areas and suggest that greater social and economic support for the elderly in rural Africa could undermine one of the key benefits of having many children. In sum, additional research, especially studies drawing on longitudinal data, is required to corroborate or refute these claims, but such studies should consider important differences by type of union, age, and sex and across multiple indicators of psychological wellbeing. 


\section{REFERENCES}

Aassve, Arnstein, Alice Goisis, and Maria Sironi. 2012. "Happiness and childbearing across Europe," Social Indicators Research 108(1): 65-86.

Aassve, Arnstein, Letizia Mencarini, and Maria Sironi. 2015. "Institutional change, happiness, and fertility,” European Sociological Review 31(6): 749-65. doi:10.1093/esr/jcv073.

Ballas, Dimitris and Danny Dorling. 2007. "Measuring the impact of major life events upon happiness." International Journal of Epidemiology 36(6): 1244-52.

Barden-O'Fallon, Janine. 2005. "Unmet fertility expectations and the perception of fertility problems in a Malawian village," African Journal of Reproductive Health 9(2): 14-25.

Bignami-Van Assche, Simona, Georges Reniers, and Alexander A. Weinreb. 2003. “An assessment of the KDICP and MDICP data quality: Interviewer effects, question reliability and sample attrition," Demographic Research 1: 31-76. doi:10.4054/DemRes.2003.S1.2.

Bongaarts, John and John Casterline. 2013. "Fertility transition: Is sub-Saharan Africa different?" Population and Development Review 38 (Supplement): 153-168.

Bove, Riley and Claudi Valeggia. 2009. "Polygyny and women's health in sub-Saharan Africa." Social Science \& Medicine 68(1): 21-29.

Brown, Susan L. 2000. "The effect of union type on psychological well-being: Depression among cohabitors versus marrieds." Journal of Health and Social Behavior 41(3): 24141. doi: $10.2307 / 2676319$

Cetre, Sophie, Andrew E. Clark, and Claudia Senik. 2016. "Happy people have children: 
Choice and self-selection into parenthood," European Journal of Population 32 (3): 44573. doi:10.1007/s10680-016-9389-x.

Clark, Andrew E., Ed Diener, Yannis Georgellis, and Richard E. Lucas. 2008. "Lags and leads in life satisfaction: A test of the baseline hypothesis," The Economic Journal 118: F222F243.

Clark, Andrew E. and Yannis Georgellis. 2013. "Back to baseline in Britain: Adaptation in the British Household Panel Survey," Economica 80: 496-512.

Clark, Shelley and Dana Hamplovà. 2013. "Single motherhood and child mortality in subSaharan Africa: A life course perspective," Demography 50(5): 1521-1549. doi 10.1007/s13524-013-0220-6).

Clark, Shelley and Sarah Brauner-Otto. 2015. "Divorce in sub-Saharan Africa: Are unions becoming less stable?" Population and Development Review 41(4): 583-605. doi: 10.1111/j.1728-4457.2015.00086.x.

Clark, Shelley, Sangeetha Madhavan, Cassandra Cotton, Dontien Beguy, and Caroline Kabiru. 2017. "Who helps single mothers in Nairobi? The role of kin support." Journal of Marriage and Family 79(4): 1186-1204.

Clark, Shelley, Alissa Koski, and Emily Smith-Greenaway. 2017. "Recent trends in premarital fertility across sub-Saharan Africa." Studies in Family Planning 48(1): 322. doi:10.1111/sifp.12013.

Corcoran, Kevin and Joel Fischer. 2013. Measures for Clinical Practice and Research: A Sourcebook. 5th ed. Oxford: Oxford University Press.

Conzo, Pierluigi, Giulia Fuochi, and Letizia Mencarini. 2017. "Fertility and life satisfaction in rural Ethiopia," Demography 54(4): 1331-51. doi:10.1007/s13524-017-0590-2. 
Deaton, Angus and Arthur A. Stone. 2014. "Evaluative and hedonic wellbeing among those with and without children at home," Proceedings of the National Academy of Sciences of the United States of America 111(4): 1328-33.

DeMaris, Alfred. 2018. "Marriage advantage in subjective well-being: Causal effect or unmeasured heterogeneity?" Marriage \& Family Review 54(4): 335-50. doi:10.1080/01494929.2017.1359812.

Dyer, Silke J. 2007. "The value of children in African countries - insights from studies on infertility," Journal of Psychosomatic Obstetrics and Gynecology 28(2): 69-77. doi:10.1080/01674820701409959.

Evenson, Ranae J. and Robin W. Simon. 2005. "Clarifying the relationship between parenthood and depression." Journal of Health and Social Behavior 46(4): 341-58. doi:10.1177/002214650504600403.

Fortes, M. 1958. "Introduction.” In The Development Cycle in Domestic Groups, edited by J. Goody. Cambridge: Cambridge University Press.

Frijters, Paul, David W. Johnston, and Michael A. Shields. 2011. "Life satisfaction dynamics with quarterly life event data," Scandinavian Journal of Economics 113(1): 190-211. doi:10.1111/j.1467-9442.2010.01638.x.

Hagedoorn, Mariet, Nico W. Van Yperen, James Coyne, Cornelia H. A. van Jaarsveld, Adelita V. Ranchor, Eric van Sonderen, and Robbert Sanderman. 2006. "Does marriage protect older people from distress? The role of equity and recency of bereavement." Psychology and Aging 21(3): 611-20.

Hess, Rosanna F., Ratchneewan Ross, and John L. Gililland Jr. 2018. “Infertility, psychological distress, and coping strategies among women in Mali, West Africa: A 
mixed-methods study," African Journal of Reproductive Health 22(1): 60-72. doi:10.29063/ajrh2018/v22i1.6.

Jennings, Elyse A., Nolwazi Mkhwanazi, and Lisa Berkman. 2018. "Receipt of emotional support among rural South African adults," Ageing \& Society, pp. 125. doi:10.1017/S0144686X18001526

Kim, Hyoun K. and Patrick C. McKenry. 2002. "The relationship between marriage and psychological well-being: A longitudinal analysis," Journal of Family Issues 23(8): 885911.

Kohler, Hans-Peter, Jere R. Behrman, and Axel Skytthe. 2005. "Partner + children = happiness? The effects of partnerships and fertility on well-being," Population and Development Review 31(3): 407-45.

Kohler, Hans-Peter, Susan C. Watkins, Jere R. Behrman, Philip Anglewicz, Iliana V. Kohler, Rebecca L. Thornton, James Mkandawire, Hastings Honde, Augustine Hawara, Ben Chilima, Chiwoza Bandawe, and Victor Mwapasa. 2015. "Cohort profile: The Malawi Longitudinal Study of Families and Health (MLSFH)," International Journal of Epidemiology 44(2): 394-404. doi:10.1093/ije/dyu049.

Kohler, Hans-Peter and Letizia Mencarini. 2016. "The parenthood happiness puzzle: An introduction to special issue." European Journal of Population 32(3): 327-38. doi:10.1007/s10680-016-9392-2.

Kohler, Iliana V., Colin F. Payne, Chiwoza Bandawe, and Hans-Peter Kohler. 2017. “The demography of mental health among mature adults in a low-income, high-HIVprevalence context," Demography 54(4): 1529-58. doi:10.1007/s13524-017-0596-9. 
Lawson, David and Mhairi A. Gibson. 2018. "Polygynous marriage and child health in subSaharan Africa: What is the evidence for harm?" Demographic Research 39(6): 177-208. https://dx.doi.org/10.4054/DemRes.2018.39.6

Madhavan, Sangeetha. 2002. "Best of friends and worst of enemies: Competition and collaboration in Polygny.” Ethnology 41(1): 69-84. doi:10.2307/4153021.

Margolis, Rachel and Mikko Myrskylä. 2011. "A global perspective on happiness and fertility," Population and Development Review 37(1): 29-56.

Musick, Kelly and Larry Bumpass. 2012. "Re-Examining the case for marriage: Variation and change in well-being and relationships." Journal of Marriage and Family, 74(1): 1-18.

Myroniuk, Tyler W. 2017. "Marital dissolutions and the health of older individuals in a rural African context." The Journals of Gerontology 72(4): 656-64.

Myrskylä, Mikko and Rachel Margolis. 2014. "Happiness: Before and after the kids," Demography 51(5): 1843-1866.

Nauck, Bernhard and Daniela Klaus. 2007. "The varying value of children: Empirical results from eleven societies in Asia, Africa and Europe," Current Sociology 55(4): 487-503.

Nelson, Katherine S., Kostadin Kushlev, and Sonja Lyubomirsky. 2014. "The pains and pleasures of parenting: When, why, and how is parenthood associated with more or less well-being?” Psychological Bulletin 140(3): 846-95. doi:10.1037/a0035444.

National Statistical Office (NSO) [Malawi], and ORC Macro. 2005. Malawi Demographic and Health Survey 2004. Calverton, Maryland: NSO and ORC Macro.

National Statistical Office (NSO) and ICF Macro. 2011. Malawi Demographic and Health Survey 2010. Zomba, Malawi, and Calverton, Maryland, USA: NSO and ICF Macro. Nomaguchi, Kei M. and Melissa A. Milkie. 2003. "Costs and rewards of children: The effects 
of becoming a parent on adults' lives." Journal of Marriage and Family 65(2): 356-74.

Peiró, Amado. 2006. “Happiness, satisfaction, and socio-economic conditions: Some international evidence," Journal of Socio-Economics 35: 348-365.

Pollmann-Schult, Matthias. 2014. "Parenthood and life satisfaction: Why don't children make people happy?" Journal of Marriage and Family 76(2): 319-36. doi:10.1111/jomf.12095.

Pollmann-Schult, Matthias. 2018. "Parenthood and life satisfaction in Europe: The role of family policies and working time flexibility." European Journal of Population 34(3): 387-411. 10.1111/jomf.12095

Ralston, Margaret. 2017. “The role of older persons' environment in aging well: quality of life, illness, and community context in South Africa." The Gerontologist 58(1): 11-120. https://doi.org/10.1093/geront/gnx091

Rizzi, Esther and Malgorzata Mikucka. 2015. "The happiness-parenthood link in a context of limited state support: The case of Switzerland.” FORS Working Papers Series, No. 2015-3. Lausanne: FORS. http://dial.uclouvain.be/pr/boreal/object/boreal:170973.

Scher, Anat and Ruth Sharabany. 2005. "Parenting anxiety and stress: Does gender play a part at three months of age?" The Journal of Genetic Psychology 166(2): 203-14. doi:10.3200/GNTP.166.2.203-214.

Shapiro, David and Tesfayi Gebreselassie. 2014. "Marriage in sub-Saharan Africa: Trends, determinants, and consequences." Population Research and Policy Review 33(2): 22955.

Smith-Greenaway, Emily and Jenny Trinitapoli. 2014. "Polygynous contexts, family structure, and infant mortality in sub-Saharan Africa," Demography 51(2): 341-66. 
Strohschein, Lisa, Peggy McDonough, Georges Monette, and Qing Shao. 2005. "Marital transitions and mental health: Are there gender differences in the short-term effects of marital status change?" Social Science \& Medicine 61(11): 2293-2303.

Stutzer, Alois and Bruno S. Frey. 2006. "Does marriage make people happy or do happy people get married?" The Journal of Socio-Economics 35: 326-347.

Umberson, Debra and Kristi Williams. 1999. "Family status and mental health," in Handbook of the Sociology of Mental Health, edited by Carol. S. Aneshensel and Jo. C. Phelan, 225-253. New York: Kluwer Academic/Plenum.

Umberson, Debra, Tetyana Pudrovska, and Corinne Reczek. 2010. "Parenthood, childlessness, and well-being: A life course perspective," Journal of Marriage and Family 72(3): 612-29. doi:10.1111/j.1741-3737.2010.00721.x.

Umberson, Debra, Mieke Beth Thomeer, and Kristi Williams. 2013. "Family status and mental health: Recent advances and future directions," in Handbook of the Sociology of Mental Health, $2^{\text {nd }}$ ed., edited by Carol. S. Aneshensel and Jo. C. Phelan, 405-431. New York: Springer Publishing.

UNDP. 2016. Human Development Report 2016: Human Development for Everyone. Human Development Report, 2016. New York, New York: United Nations Publications.

Waite, Linda J. and Maggie Gallagher. 2000. The Case for Marriage: Why Married People Are Happier, Healthier, and Better Off Financially. New York, NY: Broadway Books.

Waite, Linda J. and Evelyn L. Lehrer. 2003. "The benefits from marriage and religion in the United States: A comparative analysis," Population and Development Review 29(2): $255-75$.

Ware, John E., Mark Kosinksi, and Susan. D. Keller. 2001. SF-12: How to Score the SF-12 
Physical and Mental Health Summary Scales. Lincoln, RI: Quality Metric.

Williams, Kristi. 2003. "Has the future of marriage arrived? A contemporary examination of gender, marriage, and psychological well-being." Journal of Health and Social Behavior 44(4): 470-70. doi:10.2307/1519794.

Williams, Kristi and Debra Umberson. 2004. "Marital status, marital transitions, and health: A gendered life course perspective," Journal of Health and Social Behavior 45: $81-98$.

Wilson, Chris M., and Andrew J. Oswald. 2005. "How does marriage affect physical and psychological health? A survey of the longitudinal evidence." Warwick Economic Research Papers 728 (728).

Zimmermann, Anke C. and Richard A. Easterlin. 2006. "Happily ever after? Cohabitation, marriage, divorce, and happiness in Germany." Population and Development Review 32(3): 511-28. 


\begin{tabular}{|c|c|c|c|c|}
\hline & \multicolumn{2}{|c|}{ WOMEN } & \multicolumn{2}{|c|}{ MEN } \\
\hline & $15-49$ & & $15-49$ & \\
\hline & Years & $50+$ Years & Years & $50+$ Years \\
\hline & $\begin{array}{c}\% \text { or Mean } \\
(\mathrm{sd})\end{array}$ & $\begin{array}{c}\% \text { or Mean } \\
(\mathrm{sd})\end{array}$ & $\begin{array}{c}\% \text { or Mean } \\
(\mathrm{sd})\end{array}$ & $\begin{array}{c}\% \text { or Mean } \\
\text { (sd) }\end{array}$ \\
\hline \multicolumn{5}{|l|}{ Dependent Variables } \\
\hline SF-12 Mental Health Scale (11-73) & $55.5(8.6)$ & $53.7(9.1)$ & $57.5(6.1)$ & $56.8(6.4)$ \\
\hline Depression/Anxiety Index (0-2) & $1.7(0.5)$ & $1.6(0.6)$ & $1.9(0.4)$ & $1.8(0.5)$ \\
\hline Life Satisfaction Scale (1-5) & $4.0(1.0)$ & $3.7(1.0)$ & $4.2(0.9)$ & $3.9(0.8)$ \\
\hline \multicolumn{5}{|l|}{ Independent Variables } \\
\hline \multicolumn{5}{|l|}{ Union Status } \\
\hline Monogamously Married & 60.0 & 53.1 & 61.2 & 77.5 \\
\hline Polygynously Married & 23.0 & 27.9 & 6.6 & 19.7 \\
\hline Formerly Married & 9.3 & 19.0 & 1.9 & 2.8 \\
\hline Never Married & 7.7 & 0.0 & 30.2 & 0.0 \\
\hline Number of Children (0-25) & $3.6(2.6)$ & $7.7(2.5)$ & $2.4(2.7)$ & $8.4(3.7)$ \\
\hline Age (15-96) & $28.6(8.1)$ & $52.4(5.9)$ & $28.1(8.3)$ & $54.4(6.5)$ \\
\hline \multicolumn{5}{|l|}{ Education } \\
\hline None & 23.2 & 44.1 & 11.1 & 16.3 \\
\hline Primary & 66.4 & 53.1 & 63.4 & 74.2 \\
\hline Secondary or higher & 10.4 & 2.8 & 25.5 & 9.6 \\
\hline \multicolumn{5}{|l|}{ Religion } \\
\hline Catholic & 19.1 & 16.8 & 17.9 & 15.7 \\
\hline Muslim & 21.3 & 24.6 & 22.3 & 27.5 \\
\hline Protestant & 19.2 & 23.5 & 22.0 & 21.4 \\
\hline African Traditional & 17.0 & 16.8 & 13.0 & 14.0 \\
\hline Pentecostal/Revivalist & 17.8 & 13.4 & 18.0 & 18.0 \\
\hline Other or No Religion & 5.6 & 5.0 & 6.9 & 3.4 \\
\hline Asset Ownership (0-13) & $4.3(2.1)$ & $4.0(2.3)$ & $4.5(2.0)$ & $4.7(2.1)$ \\
\hline SF-12 Physical Health Scale (12-71) & $52.4(7.2)$ & $49.6(9.2)$ & $54.3(5.2)$ & $52.1(7.5)$ \\
\hline \multicolumn{5}{|l|}{ Region of Residence } \\
\hline Central & 33.2 & 24.6 & 32.2 & 25.3 \\
\hline South & 33.0 & 38.6 & 29.2 & 41.6 \\
\hline North & 33.9 & 36.9 & 38.5 & 33.2 \\
\hline$N$ & 983 & 179 & 678 & 178 \\
\hline
\end{tabular}




\begin{tabular}{|c|c|c|c|c|c|c|c|c|c|c|c|c|c|c|c|c|c|c|}
\hline & \multicolumn{9}{|c|}{ Interaction of Union Status \& Gender } & \multicolumn{9}{|c|}{ Interaction of Number of Children \& Gender } \\
\hline & \multicolumn{3}{|c|}{ Mental Health } & \multicolumn{3}{|c|}{ DAX } & \multicolumn{3}{|c|}{ Life Satisfaction } & \multicolumn{3}{|c|}{ Mental Health } & \multicolumn{3}{|c|}{ DAX } & \multicolumn{3}{|c|}{ Life Satisfaction } \\
\hline & Coef. & Std. Err. & Sig. & Coef. & Std. Err. & Sig. & Coef. & Std. Err. & Sig. & Coef. & Std. Err. & Sig. & Coef. & Std. Err. & Sig. & Coef. & Std. Err. & Sig. \\
\hline \multicolumn{19}{|l|}{ Union Status } \\
\hline Monogamously Married (ref) & 0.00 & -- & & 0.00 & -- & & 0.00 & -- & & 0.00 & -- & & 0.00 & -- & & 0.00 & -- & \\
\hline Polygynously Married & 0.04 & 0.09 & & 0.09 & 0.08 & & 0.09 & 0.09 & & -0.11 & 0.04 & $* *$ & -0.09 & 0.04 & ** & -0.05 & 0.04 & \\
\hline Formerly Married & -0.38 & 0.12 & $* *$ & -0.22 & 0.11 & $*$ & -0.15 & 0.12 & & -0.37 & 0.05 & $* * *$ & -0.30 & 0.05 & $* * *$ & -0.24 & 0.05 & $* * *$ \\
\hline Never Married & -0.12 & 0.06 & * & -0.10 & 0.06 & & -0.01 & 0.06 & & -0.06 & 0.05 & & -0.06 & 0.05 & & -0.04 & 0.05 & \\
\hline Number of Children & 0.00 & 0.01 & & 0.00 & 0.01 & & -0.02 & 0.01 & & 0.01 & 0.01 & & 0.01 & 0.01 & & -0.01 & 0.01 & \\
\hline Female (ref=Male) & -0.21 & 0.04 & $* * *$ & -0.11 & 0.03 & $* *$ & -0.11 & 0.04 & $* *$ & -0.17 & 0.05 & $* *$ & -0.08 & 0.05 & & -0.15 & 0.05 & $* *$ \\
\hline \multicolumn{19}{|l|}{ Interactions with Gender } \\
\hline Monogamous*Female (ref) & 0.00 & -- & & 0.00 & -- & & 0.00 & -- & & & & & & & & & & \\
\hline Polygynous*Female & -0.17 & 0.10 & & -0.22 & 0.09 & $*$ & -0.17 & 0.09 & & & & & & & & & & \\
\hline Former Married*Female & 0.00 & 0.13 & & -0.11 & 0.12 & & -0.12 & 0.13 & & & & & & & & & & \\
\hline Never Married*Female & 0.18 & 0.10 & & 0.11 & 0.10 & & -0.06 & 0.10 & & & & & & & & & & \\
\hline Number of Children*Female & & & & & & & & & & -0.01 & 0.01 & & -0.02 & 0.01 & & 0.00 & 0.01 & \\
\hline Constant & -0.29 & 0.15 & & -1.35 & 0.14 & $* * *$ & -1.89 & 0.15 & $* * *$ & -0.31 & 0.15 & $*$ & -1.36 & 0.14 & $* * *$ & -1.85 & 0.15 & $* * *$ \\
\hline LR chi2/F test & \multicolumn{3}{|c|}{$402.14 * * *$} & \multicolumn{3}{|c|}{$562.98 * * *$} & \multicolumn{3}{|c|}{$637.29 * * *$} & \multicolumn{3}{|c|}{$396.23 * * *$} & \multicolumn{3}{|c|}{$556.66^{* * *}$} & \multicolumn{3}{|c|}{$633.45 * * *$} \\
\hline $\mathrm{N}$ (Observations) & \multicolumn{3}{|c|}{4,951} & \multicolumn{3}{|c|}{4,951} & \multicolumn{3}{|c|}{4,946} & \multicolumn{3}{|c|}{4,951} & \multicolumn{3}{|c|}{4,951} & \multicolumn{3}{|c|}{4,946} \\
\hline $\mathrm{N}$ (Groups) & \multicolumn{3}{|c|}{2,193} & \multicolumn{3}{|c|}{2,193} & \multicolumn{3}{|c|}{2,192} & \multicolumn{3}{|c|}{2,193} & \multicolumn{3}{|c|}{2,193} & \multicolumn{3}{|c|}{2,192} \\
\hline
\end{tabular}

Sig.: $* \mathrm{p}<0.05, * * \mathrm{p}<0.01, * * * \mathrm{p}<0.001$

Note: Models also control for age, religion, asset ownership, education, region, and survey wave. 
Table 3. Interactions of Age Group with Union Status and Number of Children by Gender

\begin{tabular}{|c|c|c|c|c|c|c|c|c|c|c|c|c|c|c|c|c|c|c|}
\hline \multirow{3}{*}{ WOMEN } & \multicolumn{9}{|c|}{ Interaction of Union Status \& Age Group } & \multicolumn{9}{|c|}{ Interaction of Union Number of Children \& Age Group } \\
\hline & \multicolumn{3}{|c|}{$\begin{array}{c}\text { Mental Health } \\
\text { Coef. Sttd. Err Sig. }\end{array}$} & \multicolumn{3}{|c|}{$\begin{array}{l}\text { DAX } \\
\text { f. Std. Err Sig. } \\
\end{array}$} & \multicolumn{3}{|c|}{$\begin{array}{c}\text { Life Satisfaction } \\
\text { Coef. Std. Err Sig. }\end{array}$} & \multicolumn{3}{|c|}{$\begin{array}{c}\text { Mental Health } \\
\text { Coef. Std. Err Sig. }\end{array}$} & \multicolumn{3}{|c|}{$\begin{array}{c}\text { DAX } \\
\text { Coef. Std. Err Sig. }\end{array}$} & \multicolumn{3}{|c|}{$\begin{array}{r}\text { Life Satisfaction } \\
\text { Std. Err Sig } \\
\end{array}$} \\
\hline & & & & & & & & & & & & & & & & & & \\
\hline Monogamously Married (ref) & 0.00 & -- & & 0.00 & -- & & 0.00 & -- & & 0.00 & -- & & 0.00 & -- & & 0.00 & -- & \\
\hline Polygynously Married & -0.11 & 0.09 & & -0.06 & 0.09 & & -0.01 & 0.08 & & -0.14 & 0.04 & $* * *$ & -0.13 & 0.04 & $* *$ & -0.07 & 0.04 & \\
\hline Formerly Married & -0.18 & 0.08 & * & -0.09 & 0.08 & & -0.07 & 0.07 & & -0.31 & 0.05 & $* * *$ & -0.25 & 0.05 & $* * *$ & -0.20 & 0.05 & $* * *$ \\
\hline Never Married & 0.09 & 0.10 & & 0.04 & 0.10 & & -0.03 & 0.09 & & 0.06 & 0.10 & & 0.02 & 0.10 & & -0.05 & 0.09 & \\
\hline Number of Children & 0.00 & 0.01 & & 0.00 & 0.01 & & -0.01 & 0.01 & & 0.04 & 0.01 & $* *$ & 0.02 & 0.01 & $*$ & 0.02 & 0.01 & \\
\hline Younger Age Group (ref=Older group) & 0.17 & 0.07 & $*$ & 0.18 & 0.07 & $* *$ & 0.08 & 0.06 & & 0.46 & 0.12 & $* * *$ & 0.37 & 0.12 & $* *$ & 0.26 & 0.11 & $*$ \\
\hline \multicolumn{19}{|l|}{ Interactions with Age Group } \\
\hline Monogamous*Younger Age (ref) & 0.00 & -- & & 0.00 & -- & & 0.00 & -- & & & & & & & & & & \\
\hline Polygamous* Younger Age & -0.05 & 0.10 & & -0.08 & 0.10 & & -0.08 & 0.09 & & & & & & & & & & \\
\hline Formerly Married*Younger Age & -0.22 & 0.10 & $*$ & -0.26 & 0.10 & $* *$ & -0.21 & 0.09 & * & & & & & & & & & \\
\hline Number of Children*Younger Age & & & & & & & & & & -0.05 & 0.02 & $* *$ & -0.04 & 0.01 & $* *$ & -0.04 & 0.01 & $* *$ \\
\hline Constant & -1.28 & 0.15 & $* * *$ & -2.24 & 0.14 & $* * *$ & -2.38 & 0.13 & $* * *$ & -1.52 & 0.17 & $* * *$ & -2.39 & 0.16 & $* * *$ & -2.52 & 0.15 & $* * *$ \\
\hline $\mathrm{LR}$ chi2/F test & \multicolumn{3}{|c|}{$379.44 * * *$} & \multicolumn{3}{|c|}{$679.96 * * *$} & \multicolumn{3}{|c|}{$693.86^{* * * *}$} & \multicolumn{3}{|c|}{$385.28 * * *$} & \multicolumn{3}{|c|}{$680.49 * * *$} & \multicolumn{3}{|c|}{$695.72 * * *$} \\
\hline $\mathrm{N}$ (Observations) & \multicolumn{3}{|c|}{3,886} & \multicolumn{3}{|c|}{3,886} & \multicolumn{3}{|c|}{3,884} & \multicolumn{3}{|c|}{3,886} & \multicolumn{3}{|c|}{3,886} & \multicolumn{3}{|c|}{3,884} \\
\hline $\mathrm{N}$ (Groups) & & 1,738 & & & 1,738 & & & 1,738 & & & 1,738 & & & 1,738 & & & 1,738 & \\
\hline MEN & & & & & & & & & & & & & & & & & & \\
\hline Union Status & & & & & & & & & & & & & & & & & & \\
\hline Monogamously Married (ref) & 0.00 & -- & & 0.00 & -- & & 0.00 & -- & & 0.00 & -- & & 0.00 & -- & & 0.00 & -- & \\
\hline Polygynously Married & 0.08 & 0.10 & & 0.07 & 0.09 & & 0.03 & 0.10 & & 0.07 & 0.06 & & 0.09 & 0.06 & & 0.06 & 0.07 & \\
\hline Formerly Married & -0.25 & 0.14 & & -0.27 & 0.14 & & 0.06 & 0.15 & & -0.33 & 0.09 & $* * *$ & -0.22 & 0.09 & $* *$ & -0.07 & 0.09 & \\
\hline Never Married & -0.07 & 0.05 & & -0.05 & 0.05 & & 0.05 & 0.06 & & -0.09 & 0.06 & & -0.06 & 0.06 & & -0.01 & 0.06 & \\
\hline Number of Children & -0.01 & 0.01 & & 0.00 & 0.01 & & -0.01 & 0.01 & & 0.00 & 0.01 & & 0.00 & 0.01 & & 0.02 & 0.01 & \\
\hline Younger Age Group (ref=Older group) & 0.08 & 0.06 & & 0.07 & 0.06 & & 0.21 & 0.06 & $* *$ & 0.19 & 0.10 & & 0.11 & 0.10 & & 0.49 & 0.11 & $* * *$ \\
\hline Interactions with Age Group & & & & & & & & & & & & & & & & & & \\
\hline Monogamous*Younger Age (ref) & 0.00 & -- & & 0.00 & -- & & 0.00 & -- & & & & & & & & & & \\
\hline Polygamous* Younger Age & -0.03 & 0.12 & & 0.04 & 0.12 & & 0.03 & 0.13 & & & & & & & & & & \\
\hline Formerly Married*Younger Age & -0.13 & 0.18 & & 0.07 & 0.17 & & -0.19 & 0.19 & & & & & & & & & & \\
\hline Number of Children*Younger Age & & & & & & & & & & -0.02 & 0.01 & & -0.01 & 0.01 & & -0.04 & 0.01 & ** \\
\hline Constant & -0.45 & 0.16 & $* *$ & -1.71 & 0.16 & $* * *$ & -2.00 & 0.18 & $* * *$ & -0.52 & 0.17 & $* * *$ & -1.74 & 0.17 & $* * *$ & -2.19 & 0.19 & $* * *$ \\
\hline LR chi2/F test & & $37.00^{* * *}$ & & & $75.43 * *:$ & & & $25.22 * *$ & & & $38.16^{* * *}$ & & & $75.40^{* * *}$ & & & $34.09 * *$ & \\
\hline $\mathrm{N}$ (Observations) & & 2,578 & & & 2,578 & & & 2,575 & & & 2,578 & & & 2,578 & & & 2,575 & \\
\hline $\mathrm{N}$ (Groups) & & 1,188 & & & 1,188 & & & 1,187 & & & 1,188 & & & 1,188 & & & 1,187 & \\
\hline
\end{tabular}

Sig.: ${ }^{*} \mathrm{p}<0.05,{ }^{* *} \mathrm{p}<0.01,{ }^{* * *} \mathrm{p}<0.001$

Note: Models also control for religion, asset ownership, education, region, and survey wave. 
Figure 1. Psychological Wellbeing of Women and Men Aged 15-49, Random Effects Models.
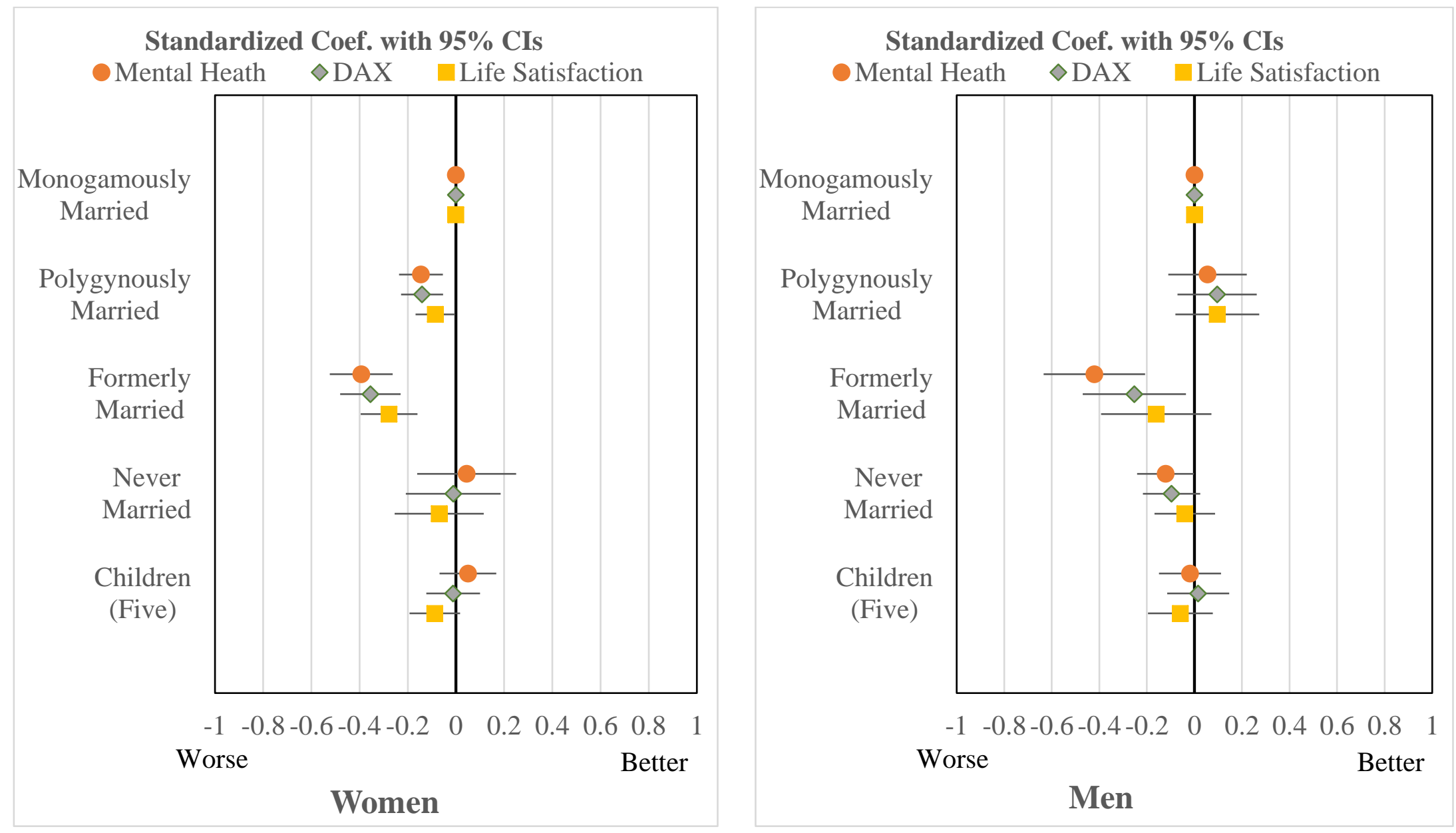

Note: Full results available in Appendix 1. Children (Five) reports the effect of having five versus no children to aid visual interpretation. 
Figure 2. Psychological Wellbeing of Women and Men Aged 15-49, Fixed Effects Models.

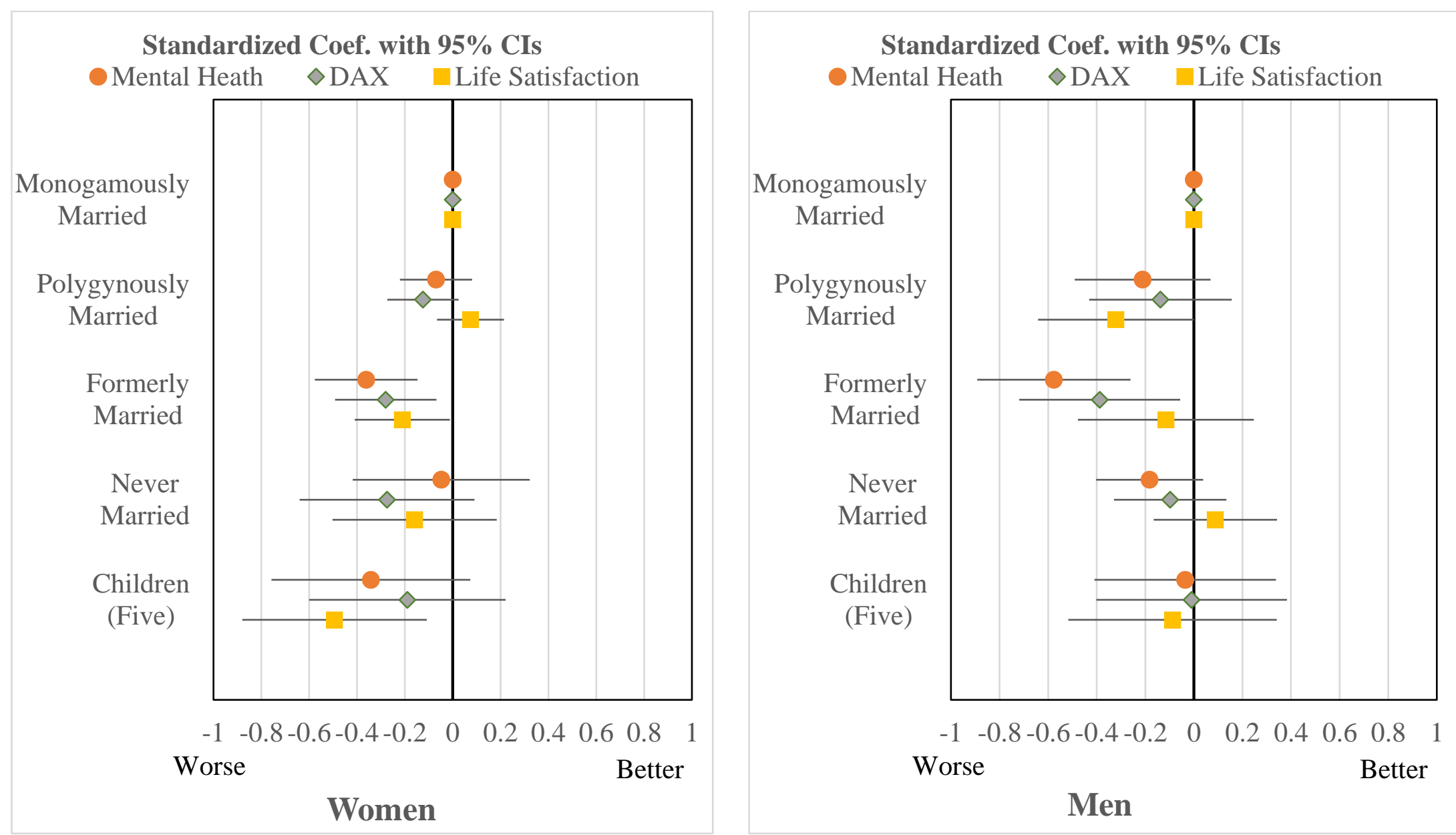

Note: Full results available in Appendix 2. Children (Five) reports the effect of having five versus no children to aid visual interpretation. 
Figure 3. Psychological Wellbeing of Women and Men Aged 50 or Older, Random Effects Models.

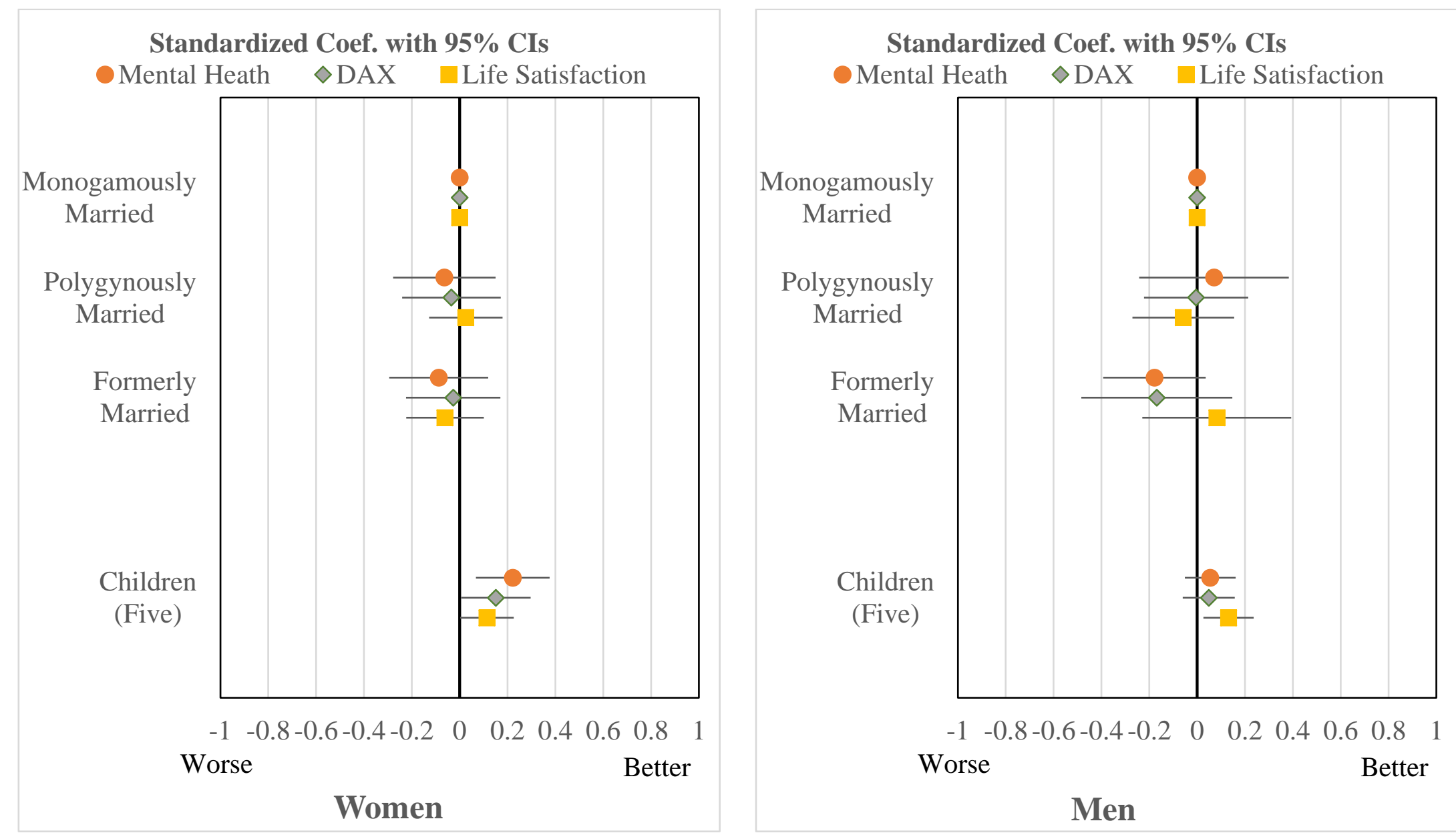

Note: Full results available in Appendix 3. Children (Five) reports the effect of having five versus no children to aid visual interpretation. 
Appendix 1. Results for Random Effects Regressions, Women and Men 15-49

\begin{tabular}{|c|c|c|c|c|c|c|c|c|c|c|c|c|c|c|c|c|c|c|}
\hline \multirow[b]{4}{*}{ Union Status } & \multicolumn{9}{|c|}{ WOMEN } & \multicolumn{9}{|c|}{ MEN } \\
\hline & \multicolumn{3}{|c|}{ Mental Health } & \multicolumn{3}{|c|}{ DAX } & \multicolumn{3}{|c|}{ Life Satisfaction } & \multicolumn{3}{|c|}{ Mental Health } & \multicolumn{3}{|c|}{ DAX } & \multicolumn{3}{|c|}{ Life Satisfaction } \\
\hline & Coef. & Std. Err. & Sig. & Coef. & Std. Err. & Sig. & Coef. & Std. Err. & Sig. & Coef. & Std. Err. & Sig. & Coef. & Std. Err. & Sig. & Coef. & Std. Err. & Sig. \\
\hline & & & & & & & & & & & & & & & & & & \\
\hline Monogamously Married (ref) & 0.00 & -- & & 0.00 & -- & & 0.00 & -- & & 0.00 & -- & & 0.00 & -- & & 0.00 & -- & \\
\hline Polygynously Married & -0.15 & 0.05 & $* *$ & -0.14 & 0.04 & $* *$ & -0.09 & 0.04 & * & 0.06 & 0.08 & & 0.10 & 0.09 & & 0.10 & 0.09 & \\
\hline Formerly Married & -0.39 & 0.07 & $* * *$ & -0.36 & 0.06 & $* * *$ & -0.28 & 0.06 & $* * *$ & -0.42 & 0.11 & $* * *$ & -0.25 & 0.11 & $*$ & -0.16 & 0.12 & \\
\hline Never Married & 0.04 & 0.10 & & -0.01 & 0.10 & & -0.07 & 0.09 & & -0.12 & 0.06 & * & -0.10 & 0.06 & & -0.04 & 0.06 & \\
\hline Number of Children & 0.01 & 0.01 & & 0.00 & 0.01 & & -0.02 & 0.01 & & 0.00 & 0.01 & & 0.00 & 0.01 & & -0.01 & 0.01 & \\
\hline Asset Ownership & 0.01 & 0.01 & & 0.01 & 0.01 & & 0.04 & 0.01 & $* * *$ & 0.01 & 0.01 & & 0.00 & 0.01 & & 0.04 & 0.01 & $* * *$ \\
\hline SF12_physical & 0.02 & 0.00 & $* * *$ & 0.04 & 0.00 & $* * *$ & 0.04 & 0.00 & $* * *$ & 0.01 & 0.00 & $* *$ & 0.03 & 0.00 & $* * *$ & 0.04 & 0.00 & $* * *$ \\
\hline Age & -0.01 & 0.00 & $* *$ & -0.01 & 0.00 & & 0.00 & 0.00 & & -0.01 & 0.00 & & -0.01 & 0.00 & & -0.01 & 0.00 & \\
\hline \multicolumn{19}{|l|}{ Religion } \\
\hline Catholic (ref) & 0.00 & -- & & 0.00 & -- & & 0.00 & -- & & 0.00 & -- & & 0.00 & -- & & 0.00 & -- & \\
\hline Muslim & 0.00 & 0.08 & & -0.03 & 0.08 & & 0.03 & 0.07 & & -0.03 & 0.09 & & -0.01 & 0.09 & & 0.10 & 0.09 & \\
\hline Protestant & -0.03 & 0.07 & & 0.03 & 0.06 & & -0.02 & 0.06 & & 0.00 & 0.07 & & 0.01 & 0.07 & & 0.00 & 0.07 & \\
\hline African Independent & -0.02 & 0.07 & & -0.03 & 0.07 & & -0.05 & 0.06 & & -0.05 & 0.08 & & -0.03 & 0.08 & & -0.01 & 0.08 & \\
\hline Pentecostal & -0.06 & 0.07 & & -0.06 & 0.06 & & 0.00 & 0.06 & & 0.02 & 0.07 & & 0.03 & 0.07 & & 0.03 & 0.07 & \\
\hline Other or None & -0.11 & 0.09 & & -0.02 & 0.08 & & -0.04 & 0.08 & & -0.14 & 0.09 & & -0.13 & 0.09 & & -0.18 & 0.09 & \\
\hline \multicolumn{19}{|l|}{ Education } \\
\hline None (ref) & 0.00 & -- & & 0.00 & -- & & 0.00 & -- & & 0.00 & -- & & 0.00 & -- & & 0.00 & -- & \\
\hline Primary & -0.07 & 0.06 & & -0.08 & 0.05 & & -0.01 & 0.05 & & -0.15 & 0.08 & & -0.16 & 0.08 & $*$ & 0.05 & 0.08 & \\
\hline Secondary or higher & -0.08 & 0.09 & & -0.13 & 0.08 & & -0.05 & 0.08 & & -0.22 & 0.09 & * & -0.18 & 0.09 & & -0.03 & 0.10 & \\
\hline \multicolumn{19}{|l|}{ Region } \\
\hline Central (ref) & 0.00 & -- & & 0.00 & -- & & 0.00 & -- & & 0.00 & -- & & 0.00 & -- & & 0.00 & -- & \\
\hline South & -0.05 & 0.07 & & -0.02 & 0.07 & & -0.17 & 0.06 & $* *$ & -0.03 & 0.08 & & -0.05 & 0.08 & & -0.25 & 0.08 & $* *$ \\
\hline North & 0.07 & 0.05 & & 0.13 & 0.05 & $*$ & -0.31 & 0.05 & $* * *$ & 0.04 & 0.06 & & 0.03 & 0.06 & & -0.37 & 0.06 & $* * *$ \\
\hline \multicolumn{19}{|l|}{ Wave } \\
\hline 4 (ref) & 0.00 & -- & & 0.00 & -- & & 0.00 & -- & & 0.00 & -- & & 0.00 & -- & & 0.00 & -- & \\
\hline 5 & -0.15 & 0.05 & $* *$ & -0.05 & 0.05 & & 0.11 & 0.04 & $*$ & -0.10 & 0.05 & $*$ & -0.04 & 0.05 & & 0.08 & 0.05 & \\
\hline 6 & -0.34 & 0.05 & $* * *$ & -0.25 & 0.05 & $* * *$ & 0.14 & 0.04 & $* *$ & -0.30 & 0.05 & $* * *$ & -0.23 & 0.05 & $* * *$ & 0.14 & 0.05 & $* *$ \\
\hline Constant & -0.72 & 0.19 & $* * *$ & -1.88 & 0.18 & $* * *$ & -2.26 & 0.17 & $* * *$ & 0.01 & 0.25 & & -0.90 & 0.25 & $* * *$ & -1.68 & 0.27 & $* * *$ \\
\hline LR chi2/F test & \multicolumn{3}{|c|}{$220.52 * * *$} & \multicolumn{3}{|c|}{$378.61 * * *$} & \multicolumn{3}{|c|}{$406.65 * * *$} & \multicolumn{3}{|c|}{$101.28 * * *$} & \multicolumn{3}{|c|}{$121.56 * * *$} & \multicolumn{3}{|c|}{$173.71 * * *$} \\
\hline $\mathrm{N}$ (Observations) & \multicolumn{3}{|c|}{3,014} & \multicolumn{3}{|c|}{3,014} & \multicolumn{3}{|c|}{3,012} & & 1,937 & & & 1,937 & & & 1,934 & \\
\hline $\mathrm{N}$ (Groups) & & 1,312 & & & 1,312 & & & 1,312 & & & 881 & & & 881 & & & 880 & \\
\hline
\end{tabular}

Sig.: *p $<0.05, * * \mathrm{p}<0.01,{ }^{* * *} \mathrm{p}<0.001$ 
Appendix 2. Results for Fixed Effects Regressions, Women and Men 15-49

\begin{tabular}{|c|c|c|c|c|c|c|c|c|c|c|c|c|c|c|c|c|c|c|}
\hline & \multicolumn{9}{|c|}{ WOMEN } & \multicolumn{9}{|c|}{ MEN } \\
\hline & \multicolumn{3}{|c|}{ Mental Health } & \multicolumn{3}{|c|}{ DAX } & \multicolumn{3}{|c|}{ Life Satisfaction } & \multicolumn{3}{|c|}{ Mental Health } & \multicolumn{3}{|c|}{ DAX } & \multicolumn{3}{|c|}{ Life Satisfaction } \\
\hline & Coef. & Std. Err & Sig. & Coef. & Std. Err. & Sig. & Coef. & Std. Err. & Sig. & Coef. & Std. Err. & Sig. & Coef. & Std. Err. & Sig. & Coef. & Std. Err. & Sig. \\
\hline \multicolumn{19}{|l|}{ Union Status } \\
\hline Monogamously Married (ref) & 0.00 & -- & & 0.00 & -- & & 0.00 & -- & & 0.00 & -- & & 0.00 & -- & & 0.00 & -- & \\
\hline Polygynously Married & -0.07 & 0.08 & & -0.12 & 0.08 & & 0.07 & 0.07 & & -0.21 & 0.14 & & -0.14 & 0.15 & & -0.32 & 0.16 & \\
\hline Formerly Married & -0.36 & 0.11 & $* *$ & -0.28 & 0.11 & $*$ & -0.21 & 0.10 & $*$ & -0.58 & 0.16 & $* * *$ & -0.39 & 0.17 & $*$ & -0.12 & 0.18 & \\
\hline Never Married & -0.05 & 0.19 & & -0.27 & 0.19 & & -0.16 & 0.17 & & -0.18 & 0.11 & & -0.10 & 0.12 & & 0.09 & 0.13 & \\
\hline Number of Children & -0.07 & 0.04 & & -0.04 & 0.04 & & -0.10 & 0.04 & $*$ & -0.01 & 0.04 & & 0.00 & 0.04 & & -0.02 & 0.04 & \\
\hline Asset Ownership & 0.00 & 0.02 & & 0.00 & 0.02 & & 0.04 & 0.02 & $*$ & 0.01 & 0.02 & & 0.02 & 0.02 & & 0.01 & 0.02 & \\
\hline SF12_physical & 0.01 & 0.00 & $*$ & 0.03 & 0.00 & $* * *$ & 0.04 & 0.00 & $* * *$ & 0.01 & 0.00 & & 0.02 & 0.01 & $* * *$ & 0.04 & 0.01 & $* * *$ \\
\hline \multicolumn{19}{|l|}{ Wave } \\
\hline 4 (ref) & 0.00 & -- & & 0.00 & -- & & 0.00 & -- & & 0.00 & -- & & 0.00 & -- & & 0.00 & -- & \\
\hline 5 & -0.14 & 0.06 & $* *$ & -0.08 & 0.06 & & 0.14 & 0.05 & $* *$ & -0.14 & 0.06 & $*$ & -0.09 & 0.06 & & 0.10 & 0.07 & \\
\hline 6 & -0.34 & 0.07 & $* * *$ & -0.29 & 0.07 & $* * *$ & 0.21 & 0.06 & $* *$ & -0.33 & 0.07 & $* * *$ & -0.28 & 0.07 & $* * *$ & 0.13 & 0.08 & \\
\hline Constant & -0.07 & 0.27 & & -1.52 & 0.27 & $* * *$ & -1.85 & 0.25 & $* * *$ & -0.02 & 0.29 & & -0.77 & 0.31 & $*$ & -1.85 & 0.34 & $* * *$ \\
\hline LR chi2/F test & \multicolumn{3}{|c|}{$12.83 * * *$} & \multicolumn{3}{|c|}{$18.61 * * *$} & \multicolumn{3}{|c|}{$15.64 * * *$} & \multicolumn{3}{|c|}{$8.57 * * *$} & \multicolumn{3}{|c|}{$6.51 * * *$} & \multicolumn{3}{|c|}{$5.96 * * *$} \\
\hline $\mathrm{N}$ (Observations) & \multicolumn{3}{|c|}{3,014} & \multicolumn{3}{|c|}{3,014} & \multicolumn{3}{|c|}{3,012} & \multicolumn{3}{|c|}{1,937} & \multicolumn{3}{|c|}{1,937} & \multicolumn{3}{|c|}{1,934} \\
\hline $\mathrm{N}$ (Groups) & \multicolumn{3}{|c|}{1,312} & \multicolumn{3}{|c|}{1,312} & \multicolumn{3}{|c|}{1,312} & \multicolumn{3}{|c|}{881} & \multicolumn{3}{|c|}{881} & \multicolumn{3}{|c|}{880} \\
\hline
\end{tabular}

Sig.: *p $<0.05, * * \mathrm{p}<0.01, * * * \mathrm{p}<0.001$ 
Appendix 3. Results for Random Effects Regressions, Women and Men 50+

\begin{tabular}{|c|c|c|c|c|c|c|c|c|c|c|c|c|c|c|c|c|c|c|}
\hline \multirow{4}{*}{ Union Status } & \multicolumn{9}{|c|}{ WOMEN } & \multicolumn{9}{|c|}{ MEN } \\
\hline & \multicolumn{3}{|c|}{ Mental Health } & \multicolumn{3}{|c|}{ DAX } & \multicolumn{3}{|c|}{ Life Satisfaction } & \multicolumn{3}{|c|}{ Mental Health } & \multicolumn{3}{|c|}{ DAX } & \multicolumn{3}{|c|}{ Life Satisfaction } \\
\hline & Coef. & Std. Err. & Sig. & Coef. & Std. Err. & Sig. & Coef. & Std. Err. & Sig. & Coef. & Std. Err. & Sig. & Coef. & Std. Err. & Sig. & Coef. & Std. Err. & Sig. \\
\hline & & & & & & & & & & & & & & & & & & \\
\hline Monogamously Married (ref) & 0.00 & -- & & 0.00 & -- & & 0.00 & -- & & 0.00 & -- & & 0.00 & -- & & 0.00 & -- & \\
\hline Polygynously Married & -0.06 & 0.11 & & -0.03 & 0.11 & & 0.03 & 0.08 & & 0.07 & 0.11 & & 0.00 & 0.11 & & -0.06 & 0.11 & \\
\hline Formerly Married & -0.09 & 0.11 & & -0.03 & 0.10 & & -0.06 & 0.08 & & -0.18 & 0.16 & & -0.17 & 0.16 & & 0.08 & 0.16 & \\
\hline Number of Children & 0.04 & 0.02 & $* *$ & 0.03 & 0.01 & $*$ & 0.02 & 0.01 & $*$ & 0.01 & 0.01 & & 0.01 & 0.01 & & 0.03 & 0.01 & $*$ \\
\hline Asset Ownership & 0.01 & 0.02 & & -0.01 & 0.02 & & 0.03 & 0.02 & & 0.01 & 0.02 & & 0.01 & 0.02 & & 0.04 & 0.02 & $*$ \\
\hline SF12_physical & 0.03 & 0.00 & $* * *$ & 0.05 & 0.00 & $* * *$ & 0.04 & 0.00 & $* * *$ & 0.02 & 0.00 & $* * *$ & 0.05 & 0.00 & $* * *$ & 0.04 & 0.00 & $* * *$ \\
\hline Age & -0.01 & 0.00 & & -0.01 & 0.00 & & 0.00 & 0.00 & & -0.01 & 0.00 & & -0.01 & 0.00 & & 0.00 & 0.00 & \\
\hline \multicolumn{19}{|l|}{ Religion } \\
\hline Catholic (ref) & 0.00 & -- & & 0.00 & -- & & 0.00 & -- & & 0.00 & -- & & 0.00 & -- & & 0.00 & -- & \\
\hline Muslim & -0.17 & 0.16 & & -0.11 & 0.15 & & -0.13 & 0.12 & & 0.19 & 0.14 & & 0.09 & 0.15 & & -0.28 & 0.14 & $*$ \\
\hline Protestant & 0.04 & 0.13 & & 0.12 & 0.13 & & 0.04 & 0.10 & & 0.02 & 0.12 & & -0.13 & 0.13 & & -0.18 & 0.12 & \\
\hline African Independent & 0.04 & 0.16 & & 0.09 & 0.15 & & -0.11 & 0.11 & & -0.20 & 0.15 & & -0.12 & 0.15 & & -0.13 & 0.14 & \\
\hline Pentecostal & 0.08 & 0.16 & & -0.07 & 0.15 & & -0.01 & 0.12 & & 0.05 & 0.13 & & 0.06 & 0.14 & & -0.05 & 0.13 & \\
\hline Other or None & 0.01 & 0.21 & & 0.11 & 0.20 & & 0.15 & 0.16 & & -0.19 & 0.19 & & 0.06 & 0.19 & & 0.01 & 0.19 & \\
\hline \multicolumn{19}{|l|}{ Education } \\
\hline None (ref) & 0.00 & -- & & 0.00 & -- & & 0.00 & -- & & 0.00 & -- & & 0.00 & -- & & 0.00 & -- & \\
\hline Primary & 0.04 & 0.10 & & 0.09 & 0.09 & & 0.14 & 0.07 & & -0.04 & 0.11 & & 0.10 & 0.11 & & -0.12 & 0.11 & \\
\hline Secondary or higher & 0.27 & 0.29 & & 0.05 & 0.28 & & 0.21 & 0.21 & & 0.03 & 0.17 & & 0.01 & 0.17 & & -0.08 & 0.17 & \\
\hline \multicolumn{19}{|l|}{ Region } \\
\hline Central (ref) & 0.00 & -- & & 0.00 & -- & & 0.00 & -- & & 0.00 & -- & & 0.00 & -- & & 0.00 & -- & \\
\hline South & 0.05 & 0.15 & & 0.12 & 0.14 & & 0.16 & 0.11 & & -0.23 & 0.12 & & -0.07 & 0.12 & & 0.05 & 0.11 & \\
\hline North & -0.14 & 0.12 & & -0.06 & 0.11 & & -0.22 & 0.09 & $*$ & -0.15 & 0.10 & & -0.15 & 0.10 & & -0.25 & 0.10 & $*$ \\
\hline \multicolumn{19}{|l|}{ Wave } \\
\hline 4 (ref) & 0.00 & -- & & 0.00 & -- & & 0.00 & -- & & 0.00 & -- & & 0.00 & -- & & 0.00 & -- & \\
\hline 5 & -0.20 & 0.11 & & -0.03 & 0.11 & & 0.19 & 0.09 & $*$ & -0.04 & 0.10 & & -0.03 & 0.09 & & 0.07 & 0.10 & \\
\hline 6 & -0.31 & 0.11 & $* *$ & -0.23 & 0.11 & $*$ & 0.14 & 0.09 & & -0.37 & 0.10 & $* * *$ & -0.38 & 0.09 & $* * *$ & -0.05 & 0.10 & \\
\hline Constant & -1.40 & 0.41 & $* *$ & -2.41 & 0.39 & $* * *$ & -2.72 & 0.30 & $* * *$ & -0.14 & 0.41 & & -1.82 & 0.42 & $* * *$ & -2.11 & 0.41 & $* * *$ \\
\hline LR chi2/F test & \multicolumn{3}{|c|}{$104.04 * * *$} & \multicolumn{3}{|c|}{$187.00 * * *$} & \multicolumn{3}{|c|}{$221.72 * * *$} & \multicolumn{3}{|c|}{$79.89 * * *$} & \multicolumn{3}{|c|}{$206.94 * * *$} & \multicolumn{3}{|c|}{$107.91 * * *$} \\
\hline N (Observations) & \multicolumn{3}{|c|}{869} & \multicolumn{3}{|c|}{869} & \multicolumn{3}{|c|}{869} & \multirow{2}{*}{\multicolumn{3}{|c|}{641}} & & 641 & & & 641 & \\
\hline $\mathrm{N}$ (Groups) & & 426 & & & 426 & & & 426 & & & & & & 307 & & & 307 & \\
\hline
\end{tabular}

Sig.: *p $<0.05, * * \mathrm{p}<0.01, * * * \mathrm{p}<0.001$ 